JURNAL KEBIDANAN

Vol 6, No 2, April 2020 : 186-189

\title{
FAKTOR RISIKO KELAINAN LETAK PADA IBU HAMIL : STUDI KARAKTERISTIK GESTASI PADA RUMAH SAKIT SWASTA DI KABUPATEN BULELENG, BALI
}

\author{
Yopita Triguno ${ }^{1}$, Putu Dian Prima Kusuma Dewi², Ni Made Karlina Sumiari Tangkas ${ }^{3}$, Kadek Ayu \\ Suarmini ${ }^{4}$, Ni Komang Emi Wahyuni ${ }^{5}$, Putu Juli Asmari ${ }^{6}$ \\ 1Dosen Kebidanan Sekolah Tinggi IImu Kesehatan Buleleng \\ Korespondensi Email (yopipita28@gmail.com) \\ 2Dosen Kebidanan Sekolah Tinggi IImu Kesehatan Buleleng \\ Email dian_pkd@yahoo.co.id \\ 3Dosen Kebidanan Sekolah Tinggi IImu Kesehatan Buleleng \\ Email karlinasumiari@gmail.com \\ ${ }^{4}$ Dosen Kebidanan Sekolah Tinggi Ilmu Kesehatan Buleleng \\ Email kadekayusuarmini@yahoo.com \\ 5Mahasiswa S1-Kebidanan \\ Email emiwahyuni@gmail.com \\ 6Mahasiswa D3-Kebidanan \\ Email Juliasmari@gmail.com
}

\begin{abstract}
Background Abnormalities in the location of pregnancy become a pathological condition that is often overlooked in pregnancy. Traumatic and risk of illness such as prolonged labor, premature rupture of membranes is very likely to occur in conditions of abnormalities.

Purpose of analyzing the most dominant gestational characteristics is increasing the risk of misalignment in pregnant women.

Method Analytical research methods with a retrospective approach and cross-sectional retrieval. This study uses secondary data from mothers who gave birth at Kertha Usada Hospital in the period of January - June 2016. The analysis used was logistic regression using STATA SE version 12. The sample consisted of 718 people using secondary data.

The results of this study showed that the location abnormalities were $7.94 \%$, did not experience placenta previa $98.19 \%$, multipara $68.06 \%$, gestation more than 37 weeks $93.72 \%$ and birth weight $89.97 \%$. Parity in the multipara category, which gives birth more than once, increases the risk of localized abnormalities by up to 5 times greater than primipara ( $p$ value 0.01 ). parity with multipara category as the most dominant factor increases the risk of abnormalities in pregnant women with aOR value of 2.33 (Cl 1.15-4.70 p value 0.01)

Conclusion the most dominant factor increasing the risk of misalignment in pregnant women is multiparous parity

Suggestion Early detection of these abnormalities is routinely carried out during the pregnancy process, especially among multiparous mothers.
\end{abstract}

Keywords: Parity, Gestation, Location Disorders

\section{ABSTRAK}

Latar Belakang Kelainan letak pada kehamilan menjadi kondisi patologi yang sering terabaikan pada kehamilan. Traumatik dan risiko kesakitan seperti partus lama, ketuban pecah dini sangat mungkin terjadi pada kondisi kelainan letak.

Tujuan untuk menganalisis karakteristik gestasi yang paling dominan meningkatkan risiko kelainan letak pada ibu hamil.

Metode Penelitian analitik dengan pendekatan secara retrospektif dan pengambilan secara crossectional.Penelitian ini menggunakan data sekunder dari ibu yang melahirkan di Rumah Sakit Kertha Usada pada periode waktu Januari - Juni 2016.Analisis yang digunakan adalah regresi logistic menggunakan STATA SE versi 12. Sampel berjumlah 718 orang menggunakan data sekunder.

Hasil penelitian ini menunjukkan bahwa kelainan letak 7.94\%, tidak mengalami placenta previa $98.19 \%$, multipara $68.06 \%$, gestasi lebih dari 37 minggu $93.72 \%$ dan berat badan lahir $89.97 \%$. Paritas dalam kategori 
multipara yaitu melahirkan lebih dari satu kali meningkatkan risiko kelainan letak hingga 5 kali lebih besar dibandingkan primipara ( $p$ value 0.01 ). paritas dengan kategori multipara sebagai faktor yang paling dominan meningkatkan risiko kelainan letak pada ibu hamil dengan nilai aOR $2.33(\mathrm{Cl} 1.15-4.70 \mathrm{p}$ value 0.01$)$

Kesimpulan faktor yang paling dominan meningkatkan risiko kelainan letak pada ibu hamil adalah paritas multipara

Saran Sebaiknya deteksi dini tentang kelainan letak ini rutin dilakukan selama proses kehamilan teruatam pada ibu multipara.

Kata Kunci : Paritas, Gestasi, Kelainan Letak

\section{PENDAHULUAN}

Kesehatan Ibu dan Anak menjadi salah satu indikator yang menyatakan derajat kesehatan sebuah Negara. Menurut Data Survey Demografi Kesehatan Indonesia (SDKI) tahun 2012 rata-rata kematian ibu melonjak dari data sebelumnya tahun 2007 dari 228/100.000 kelahiran hidup mencapai 359/100.000 kelahiran hidup. Penyebab utama yang tercatat adalah masih ditempati oleh perdarahan post partum $28 \%$, eklampsia $24 \%$ dan Infeksi 11\% (Sudarmi, 2013).

Kelainan letak merupakan suatu kondisi janin dengan posisi terbawah selain kepala, kelaianan letak ini dilaporkan dalam jumlah yang bervariasi pada setipa tempat di Indonesia (Puji Setiana, Herawati, 2019; Sari, 2013). Kejadian kelainan letak janin dalam rahim ditemukan sekitar 3 - 4\% dengan presentasi bokong dari seluruh persalinan (Manuaba, 2012). Traumatik dan risiko kesakitan seperti partus lama, ketuban pecah dini sangat mungkin terjadi pada kondisi kelainan letak (Mariam, 2019).

Kelainan letak tentunya dapat dideteksi sejak dini melalui pemeriksaan antenatal yang teratur ke petugas kesehatan. Pemerintah telah menyusun program minimal empat kali untuk pemeriksaan kehamilan. Kelainan letak juga masuk dalam kategori kehamilan risiko tinggi yang tidak bisa untuk dilahirkan secara normal, walaupun terdapat beberapa kondisi kelainan letak masih bisa untuk lahir normal (Dyah Puji Astuti, Kusumastuti, 2019; Rinata, 2017).

Penelitian ini bertujuan untuk mengetahui karakteristik gestasi yang paling dominan dapat meningkatkan risiko kelainana letak pada ibu hamil. Studi dikhususkan pada karakteristik gestasi yang dimiliki oleh responden sebagai factor internal yang dikaji.

\section{METODE PENELITIAN}

Penelitian ini merupakan penelitian analitik dengan pendekatan secara retrospektif dan pengambilan secara crossectional. Penelitian ini menggunakan data sekunder dari ibu yang melahirkan di Rumah Sakit Kertha Usada pada periode waktu Januari - Juni 2016.

Data dikumpulkan dengan menggunakan formulir pengumpulan data yang masih dalam bentuk hard copy dibuat ke dalam bentuk soft copy (dalam bentuk microsoft excel) untuk memudahkan analisis.. Jumlah data yang terkumpul sebanyak 718 rekam medis dengan jangka waktu penelitian selama enam bulan. Instrument penelitian yang digunakan adalah lembar pengumpulan data. Data dianalisis menggunakan analisis multivariat regresi logistic menggunakan metode backward, eksistensi variabel confounding ditetapkan dengan signifikansi $5 \%$ dengan program software STATA SE 12. Analisis multivariabel dilakukan untuk mendapatkan model yang bisa menerangkan variable yang meningkatkan risiko kelainan letak pada ibu hamil.

Tujuan dari kegiatan penelitian ini adalah menganalisis variabel yang paling dominan meningkatkan risiko kelainan letak pada ibu hamil. Hasil ini tentunya dapat memberikan kontribusi kedepan sebagai acuan dalam pemberian konseling dan bimbingan pada ibu hamil sehingga dapat menurunkan risiko dan meningkatkan deteksi dini atas kelainan yang terjadi pada ibu hamil.

\section{HASIL DAN PEMBAHASAN}

Hasil penelitian menunjukkan bahwa proporsi kelainan letak pada ibu hamil sebesar 57 (7.94\%).

Tabel 1.

Karakteristik Gestasi Ibu Hamil di RSU Kertha Usada

\begin{tabular}{lcc}
\hline \multirow{2}{*}{ Karakteristik } & \multicolumn{2}{c}{ Responden } \\
\cline { 2 - 3 } & $\mathrm{n}$ & $\%$ \\
\hline \multicolumn{1}{c}{1} & 2 & 3 \\
\hline Kelainan Letak & & \\
$\quad$ Tidak & 661 & 92.06 \\
Ya & 57 & 7.94 \\
\hline Placenta Previa & & \\
$\quad$ Tidak & 705 & 98.19 \\
Ya & 13 & 1.81 \\
\hline Paritas & & \\
$\quad$ Primipara & 229 & 31.94 \\
$\quad$ Multipara & 488 & 68.06 \\
\hline
\end{tabular}




\begin{tabular}{lcc}
\hline Gestasi & & \\
$\quad \leq 37$ Minggu & 45 & 6.28 \\
$>37$ Minggu & 672 & 93.72 \\
\hline Berat Badan Lahir & & \\
$>2500 \mathrm{Gr}$ & 646 & 89.97 \\
$<2500 \mathrm{Gr}$ & 72 & 10.03 \\
\hline
\end{tabular}

Berdasarkan tabel 1 menunjukkan bahwa karakteristik gestasi pada ibu hamil di RSU Kertha Usada yaitu kelainan letak $7.94 \%$, tidak mengalami placenta previa $98.19 \%$, multipara $68.06 \%$, gestasi lebih dari 37 minggu $93.72 \%$ dan berat badan lahir $89.97 \%$.

Tabel 2.

Bivariat Kelainan Letak dan Karakteristik Gestas Pada Ibu Hamil di RSU Kertha Usada

\begin{tabular}{lcc}
\hline \multicolumn{1}{c}{ Karakteristik } & OR & $\mathrm{p}$ \\
\hline \multicolumn{1}{c}{1} & 2 & 3 \\
\hline Placenta Previa & 1.00 (ref) \\
\hline Tidak & 0.001 & 0.97 \\
\hline Ya & & \\
\hline Paritas & \\
\hline Primipara & 1.00 ref) \\
\hline Multipara & 5.90 & $0.01^{*}$ \\
\hline Gestasi & & \\
\hline$\quad \leq 37$ Minggu & 1.00 ref) \\
\hline >37 Minggu & 0.05 & 0.81 \\
\hline Berat Badan Lahir & & \\
\hline$>2500 \mathrm{Gr}$ & 1.00 ref) \\
\hline$<2500 \mathrm{Gr}$ & 1.10 & 0.29 \\
\hline
\end{tabular}

Tabel 3.

Multivariat Faktor Risiko Kelainan Letak Pada Ibu Hamil di RSU Kertha Usada

\begin{tabular}{lcc}
\hline \multicolumn{1}{c}{ Karakteristik } & a OR $(\mathrm{Cl})$ & $\mathrm{p}$ \\
\hline \multicolumn{1}{c}{ Placenta Previa } & 2 & 3 \\
\hline Tidak & $1.00(\mathrm{ref})$ & \\
\hline Ya & $0.82(0.10-6.68)$ & 0.86 \\
\hline Paritas & & \\
\hline Primipara & 1.00 ref $)$ & \\
\hline Multipara & $2.33(1.15-4.70)$ & $0.01^{*}$ \\
\hline Gestasi & & \\
\hline <37 Minggu & 1.00 ref $)$ & \\
\hline$>37$ Minggu & $1.06(0.33-3.45)$ & 0.92 \\
\hline Berat Badan Lahir & & \\
\hline$>2500 \mathrm{Gr}$ & 1.00 ref $)$ & \\
\hline$<2500 \mathrm{Gr}$ & $1.170(0.71-4.09)$ & 0.24 \\
\hline
\end{tabular}

Tabel 2 diatas menunjukkan dari analisa bivariate bahwa terdapat dua variabel yang berhubungan dengan kelainan letak pada ibu hamil yaitu KPD dan Multipara. Paritas dalam kategori multipara yaitu melahirkan lebih dari satu kali meningkatkan risiko kelainan letak hingga 5 kali lebih besar dibandingkan primipara ( $p$ value 0.01 ). Syarat untuk dimasukkan ke dalam model multivariat yiatu dengan nilai $p$ value $<0.25$. Namun pada penelitian ini seluruh variable dimasukkan ke dalam model dengan pertimbangan potensi dari variabel terhadap kelainan letak.

Tabel 3 diatas menunjukkkan bahwa paritas dengan kategori multipara sebagai faktor yang paling dominan meningkatkan risiko kelainan letak pada ibu hamil dengan nilai aOR $2.33(\mathrm{Cl}$ $1.15-4.70 \mathrm{p}$ value 0.01 ).

Kelainan letak menjadi salah satu kondisi patologi pada ibu hamil. Secara filosofi dan prinsipnya bahwa kehamilan adalah suatu proses yang alami dan natural, walaupun pada waktu tertentu bisa mengarah pada kondisi yang tidak normal atau patologi (Cooper, 2011). Makadari itu kehamilan memerlukan pengelolaan dan monitoring yang baik sehingga kelainan dan kondisi patologi dapat terdeteksi lebih dini. Kelainan letak yang paling banyak terjadi pada ibu hamil merupakan jenis malposisi dan mal presentasi. Posisi yang fisiologis dengan kepala bayi pada bagian terbawah Rahim (Bobak, 2005; Cooper, 2011). Kondisi yang paling banyak yaitu letak kepala $(97 \%)$ dan letak sungsang atau letak bokong (2,5 - $3 \%$ )(Puji Setiana, Herawati, 2019).

Penelitian ini menunjukkan bahwa paritas dalam kategori sudah pernah melahirkan atau multipara meningkatkan risiko kelainan letaka pada ibu hamil hingga lima kali dibandingkan primipara. Kondisi ibu multipara yang sudah pernah melahirkan secar normal, mengalami peregangan otot Rahim yang lebih maksimal dibandingkan primipara. Hal ini yang memicu ruang gerak dan volume di dalam rahim lebih besar sehingga posisi bayi dapat mengalami kelainan (Mariam, 2019).

Berat badan bayi juga memberikan kontribusi pada kelainan letak, dimana bayi dengan berat badan kurang dari 2500 gram cenderung lebih berisiko mengalami kelainan letak (Nurdiyana, 2013; Stone et al., 2017). Berbeda dengan hasil temuan pada penelitian ini walaupun melalui analisis multivariat menunjukkan berat badan < 2500 gram meningkatakn risiko 1.17 kali (aOR 1.17 $p$ value 0.24 ) namun tidak bermakna secara statistic pada data ini. Berat badan bayi yang kurang dari 2500 gram sangat erat kaitanya dengan kondisi umur kehamilan yang belum matur atau prematur. Kondisi prematur dan berat badan kurang membuat ruang gerak di dalam Rahim luas, dan gaya gravitasi tidak terjadi sehingga letak bokong atau 
kelainan letak sering terjadi. Pada kondisi umur kehamilan yang belum cukup bulan kelainan letak sering terjadi karena berat kepala lebih kecil dari berat badan bagia bawah(Bobak, 2005; Khoirunnisa, 2010). Kelainan letak juga dilaporkan pada beberapa kasus partus lama sehingga dapat meningkatkan risiko kesakitan dan trauma pada ibu bersalin (Mariam, 2019). Walaupun persentase kejadian kelainan letak hanya $2.5-3 \%$ namun jika tidak dilakukan pendeteksian sejak dini akan menimbulkan masalah yang sifatnya patologi (Mariam, 2019; Puji Setiana, Herawati, 2019; Yusuf, 2019). Pengelolaan dan asuhan kehamilan melalui kunjungan antenatal yang teratur pada ibu hamil sangat penting dilakukan. Bidan dan Dokter Spesialis Kandungan memiliki peran yang sangat penting dalam melakukan deteksi ini. Bidan melalui teknik palpasi Leopold I dan III dapat memperkirakan kelainan letak dan dapat dibandingkan melalui hasil USG (ultra sonografi) yang dilakukan oleh dokter. Makadari itu ibu hamil perlu melakukan deteksi dini dan pemeriksaan USG teruatam memasuki umur kehamilan 22 minggu ke atas. Budaya yang berkembang di masyarakat bahwa jika anak pertama dnegna posisi kepala dibawah maka anak kedua dan seterusnya dipastikan memiliki posisi yang sama tidak bisa menjadi jaminan mutlak.

\section{KESIMPULAN}

Proposi kelainan letak yaitu $7.24 \%$ dari total 718 ibu hamil yang tercatat. Paritas dengan kategori multipara sebagai faktor yang paling dominan meningkatkan risiko kelainan letak pada ibu hamil dengan nilai aOR $2.33(\mathrm{Cl} 1.15-4.70 \mathrm{p}$ value 0.01 ).

\section{SARAN}

Sebaiknya deteksi dini tentang kelainan letak ini rutin dilakukan selama proses kehamilan teruatama pada ibu multipara.

\section{DAFTAR PUSTAKA}

Bobak, L. J. (2005). Buku Ajar Keperawatan Maternitas Edisi 4 (Renata Komalasari (ed.); 4th ed.). EGC.

Cooper, F. \&. (2011). Myles Buku Ajar Bidan edisi 14. EGC.

Dyah Puji Astuti, Kusumastuti, O. (2019). Pemeriksaan Terintegrasi sebagai Upaya Deteksi Dini Faktor Resiko Penyulit dan Komplikasi Pada Ibu Hamil. In The 10th
University Research Colloqium 2019.

Khoirunnisa, S. \& E. (2010). Asuhan Kebidanan Neonatus, Bayi, dan Anak Balita. Nuha Medika.

Mariam, E. (2019). Gambaran Kelainan Janin dan Faktor Predisposisi pada Ibu Bersalin yang Mengalami Partus Lama Di RSB Permata Hati Metro. Jurnal Kesehatan "Akbid Wira Buana," 6(3), 1-7.

Nurdiyana, S. (2013). Gambaran Karakteristik Ibu Bersalin Dengan Letak Sungsang di RS Kesdam Jaya Tahun 2018. Journal of Chemical Information and Modeling, 53(9), 1689-1699.

https://doi.org/10.1017/CB0978110741532 4.004

Puji Setiana, Herawati, S. (2019). Hubungan kelainan letak janin , preeklamsia, ketuban pecah dini dengan persalinan sectio caesarea. Jurnal Kesehatan Dan Pembangunan, 9(18), 69-75.

Rinata, E. (2017). Prinsip Deteksi Dini Komplikasi Pada Ibu Hamil.

Sari, N. I. (2013). Hubungan Paritas dan Kelainan Letak dengan Kejadian Ketuban Pecah Dini Pada Ibu Bersalin di UPT Puskesmas Gajah Mada Tembilahan Tahun 20122017. Journal of Chemical Information and Modeling, 53(9), 1689-1699. https://doi.org/10.1017/CBO978110741532 4.004

Stone, P. R., Burgess, W., McIntyre, J. P. R., Gunn, A. J., Lear, C. A., Bennet, L., Mitchell, E. A., \& Thompson, J. M. D. (2017). Effect of maternal position on fetal behavioural state and heart rate variability in healthy late gestation pregnancy. Journal of Physiology, 595(4), 1213-1221. https://doi.org/10.1113/JP273201

Sudarmi. (2013). Hubungan Ketuban Pecah Dini $\geq$ 12 Jam Dengan Gawat Janin Di Ruang Bersalin RSUP NTB. Media Bina IImiah, 7 No 5.

Yusuf, S. F. (2019). Pengaruh Paritas dan Sumber Informasi Terhadap Kehamilanresiko Tinggi pada lbu Hamil di Kecamatanpanyabungan Susi Febriani Yusuf STIKes Darmais Padangsidimpuan. Jurnal Kesehatan IImiah Indonesia, 4, 126132.

file://C:/Users/ASUS/Downloads/dampak risti.pdf 